\title{
On the cascading effects of residential-scale PV disconnection due to voltage rise
}

DOI:

10.1109/PESGM.2014.6939428

Link to publication record in Manchester Research Explorer

\section{Citation for published version (APA):}

Navarro, A., \& Ochoa, L. F. (2014). On the cascading effects of residential-scale PV disconnection due to voltage rise. In IEEE/PES General Meeting 2014 (pp. 1-5) https://doi.org/10.1109/PESGM.2014.6939428

\section{Published in:}

IEEE/PES General Meeting 2014

\section{Citing this paper}

Please note that where the full-text provided on Manchester Research Explorer is the Author Accepted Manuscript or Proof version this may differ from the final Published version. If citing, it is advised that you check and use the publisher's definitive version.

\section{General rights}

Copyright and moral rights for the publications made accessible in the Research Explorer are retained by the authors and/or other copyright owners and it is a condition of accessing publications that users recognise and abide by the legal requirements associated with these rights.

\section{Takedown policy}

If you believe that this document breaches copyright please refer to the University of Manchester's Takedown Procedures [http://man.ac.uk/04Y6Bo] or contact uml.scholarlycommunications@manchester.ac.uk providing relevant details, so we can investigate your claim.

\section{OPEN ACCESS}




\title{
On the Cascading Effects of Residential-Scale PV Disconnection Due to Voltage Rise
}

\author{
Alejandro Navarro-Espinosa and Luis F. Ochoa \\ School of Electrical and Electronic Engineering \\ The University of Manchester \\ Manchester, UK \\ alejandro.navarroespinosa@manchester.ac.uk, luis_ochoa@ieee.org
}

\begin{abstract}
Photovoltaic penetration in LV networks can produce voltage rise above the limits, resulting in the automatic disconnection of panels. This voltage-driven disconnection of particularly single-phase $P V$ panels combined with the unbalance nature of $\mathrm{LV}$ networks might produce a further voltage rise in one of the other phases. This can result in a new PV disconnection. This paper analyses to which extent the risk of PV cascading exists in LV networks. A 5-minute time-series power flow analysis is adopted using a real LV network (7 feeders and 346 customers) in the North West of England. The results indicate that the risk of cascading does exist. However, the proportion of cascading disconnections is likely to be small (although increases with PV penetration). Moreover, cascading disconnections happen mostly in the period after the first automatic disconnection(s). Consequently, the actual cascading nature is very limited.
\end{abstract}

Index Terms-- low voltage networks, low carbon technologies, photovoltaic panels, power curtailment.

\section{INTRODUCTION}

The high penetration of photovoltaic panels in distribution networks can produce some technical issues, such as voltage rise, increase in energy losses, more harmonic content, etc. [1][2]. In particular, voltage rise is the main problem for $\mathrm{LV}$ networks with significant connections of residential-scale photovoltaic (PV) panels (e.g., 1 to $4 \mathrm{kWp}$ in the UK), appearing earlier than congestion problems [3].

One of the traditional measures adopted by UK Distribution Network Operators (DNOs) to limit the impact of residential-scale PV generation is the imposition of voltage limits by which PV panels have to be automatically disconnected (UK Engineering Recommendation G83 [4]). Due to this, each PV inverter has a local control to allow the corresponding disconnection. Similar practices exist around the world. For instance, in Canada, the voltages for disconnection and re-connection are 1.1 and 1.09 p.u., respectively [5]. In Europe, the thresholds for the automatic disconnection and reconnection are stated in [6], where different countries have different values but all of them in the range of 1.06 and 1.15 p.u.

This work has partly been funded by Electricity North West Limited (ENWL), UK, through the Ofgem's Low Carbon Networks Fund Tier 1 Project “LV Network Solutions”, 2011-2014.
Beside the obvious reduction of clean energy production, this voltage management approach does not present any additional problem in ideally balanced LV networks. Unfortunately, LV networks with predominant single-phase connections are topologically highly unbalanced which adds to the non-coincident behaviour among household consumption. For this particular type of networks, the automatic PV disconnection could have negative effects. In fact, as reported in [7] through a simple feeder, the disconnection of one PV panel produces a voltage reduction in the same phase but it might also cause a voltage increase in the other two phases. Hence, if the voltage was already high in one of the other phases and the voltage increase is enough to reach the maximum disconnection limit, a new PV panel will be disconnected. The repetition of this phenomenon is hereafter called PV disconnection cascading.

It is important to highlight, that the simple feeder used in [7] was limited to only three loads. Furthermore, the disconnection analysis is done from the loads (and corresponding PV panels) closes to the distribution transformer to those in the remote end of the feeder. Although this might be a plausible scenario, in practice, voltage rise issues tend to appear first for PV installations connected to those customers at the remote end of the feeders [8].

In order to adequately and realistically assess the locational effects of high PV penetrations and the corresponding risk of PV disconnection cascading, this paper studies a real LV network in the North West of England adopting a detailed PV control model. In addition, a Monte Carlo approach is considered in order to cater for the uncertainties involving PV size, location and household demand.

This paper is structured as follows: section II describes the input data including the network, load and PV profiles. The methodology is explained in section III and the cascading effect is exemplified in section IV. Section V extends the study for two voltage disconnection limits. The main results are discussed in section VI. Finally, conclusions are drawn in section VII. 


\section{Accepted Paper}

\section{INPUT DATA}

To assess the performance of the automatic PV disconnection on LV feeders, it is necessary to produce adequate load and generation profiles as well as a network model. The time-series behaviour of loads and PV generation are created by using the open source tool presented in [9]. Although these profiles have an original resolution of 1 minute, here they are aggregated in 5 minutes. A real LV network from the North West of England is adopted. It is comprised of seven feeders (total length of $7.6 \mathrm{~km}$ ) and 346 customers (modelled as domestic un-restricted).

The topology, type of conductor and phase connection for each customer are fully modelled. Table 1 shows the length and number of customers per feeder. Fig. 1 depicts the seven feeders (each feeder has a different colour) and the $11 \mathrm{kV} / 400 \mathrm{~V}$ transformer (red triangle). The typical line-to-line voltage of $415 \mathrm{~V}$ at the transformer busbar was considered throughout the simulations.

\section{MethodOLOGY}

The methodology proposed to analyse the risk (or probability) of voltage-driven PV disconnection cascading is based on the Probabilistic Impact Assessment Tool presented in [3]. The strategy is applied feeder by feeder and it consists in the random allocation of load and PV profiles (daily profiles with 5 minutes resolution) along the feeder in order to cater for their uncertain behavior and location. The load and PV profiles are implemented by using [9] and by following the UK statistics regarding the number of people per home [10] and the size of the residential PV panels [11]. The same sun radiation profile is assumed over the feeder in each simulation. This is done for a given penetration level, from 0 to $100 \%$ (percentage of houses with PV generation in the feeder), and repeated one hundred times.

For the purpose of this analysis, the automatic disconnection and reconnection is incorporated to the Probabilistic Impact Assessment Tool. According to the European Standard [6], for the UK case, the automatic PV disconnection is executed when the rms 10 -minute mean value (consistent with EN 50160 [12]) is bigger than or equal to 264V (phase to neutral). This limit was updated in [4] to 262.2V equivalent to 1.14 p.u.

It is important to clarify that the $262.2 \mathrm{~V}$ limit is used only in Great Britain. For example, in the case of Ireland, Finland and Spain, this limit is equal to 253V (1.1 p.u). To cope with these differences, the analysis will be implemented for two voltage limits: 1.1 p.u. and 1.14 p.u. The reconnection is made when the voltage in the connection point is again lower than the specific limit. Thus, the control action (disconnection and reconnection of PV panels) is implemented inside of each power flow simulation according to [4] assuming a time step (control cycle) of 5 minutes.

Given the changing nature of load and solar radiation, two cases (without and with PV control) with the same inputs are investigated to determine where negative effects are the result of PV disconnection or simply higher solar radiation and/or sudden demand reduction. For each time step in one particular simulation, these two cases are solved by using a time-series
TABLE 1

LENGTH AND CUSTOMER NUMBER PER FEEDER

\begin{tabular}{c|c|c}
\hline Feeder & Length $(\mathrm{m})$ & $\begin{array}{c}\text { No. of } \\
\text { Customers }\end{array}$ \\
\hline 1 & 1,613 & 63 \\
\hline 2 & 1,418 & 57 \\
\hline 3 & 1,107 & 50 \\
\hline 4 & 1,630 & 87 \\
\hline 5 & 1,045 & 61 \\
\hline 6 & 269 & 6 \\
\hline 7 & 559 & 22 \\
\hline
\end{tabular}

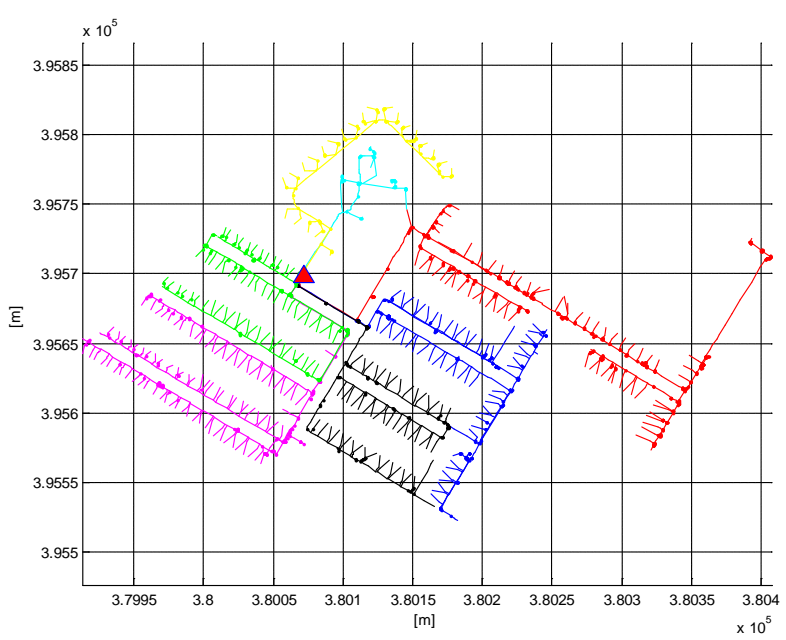

Figure 1. LV network topology.

three-phase power flow in OpenDSS [13]. These cases are:

- Case 1: Scenario without control strategy. After the simulation, the voltages at the connection point of each customer are stored.

- Case 2: Scenario with control strategy. After the simulation, the following parameters are stored: the voltages for each customer, the periods when one or more PV are disconnected, and the corresponding location.

With the results from each case it is possible to compare them for each time step $\left(t_{i}\right)$. If there is one or more disconnections in $t_{i}$ for Case 2 , then the period $t_{i+1}$ should be checked.

- If the period $t_{i+1}$ for Case 2 has one or more PV disconnected, this could imply a cascading effect. To check this, the voltages are compared with the same period $t_{i+1}$ for the Case 1 . Thus, if the voltages in Case 2 are bigger than in Case 1 (for the other phases), then there is a cascading effect. In contrast, if the voltages in Case 2 are equal or lower than Case 1 , then negative effect is not due to cascading.

- If the period $t_{i+1}$ for Case 2 does not have any disconnection, then there is no cascading effect. Nonetheless, the voltages are still compared for the same period $t_{i+1}$ with Case 1 . This is to observe any potential voltage rise. 


\section{Accepted Paper}

\section{UNDERSTANDING PV CASCADING EFFECTS}

To have a better understanding about the phenomenon under analysis, the voltages for all the customers of feeder 1 (63 customers) for a period before and after a voltage-driven $\mathrm{PV}$ disconnection are shown in Fig. 2. This example is for a $50 \%$ of penetration level and for the midday of a weekday in June (UK summer). As it can be observed, several customers in phase B reach the maximum limit; therefore, the PV panels associated to them are disconnected. Consequently, in the period after, the voltages in phase B decreased (dashed black line). Nonetheless, the voltages in phase $\mathrm{A}$ and $\mathrm{C}$ increased after the disconnection (dashed red and blue lines).

In order to verify that the voltage rise in the period after is because of the latest PV disconnection and not because of changes in sun radiation and/or demand, the voltages are compared with those for the same period and same conditions without any control strategy in Fig. 3 (as mentioned in the previous section). In this figure, it is possible to note that the voltages without control in the period after are similar to those before the latest disconnection (Fig. 2). Indeed, there was no major variation in the demand or sun radiation.

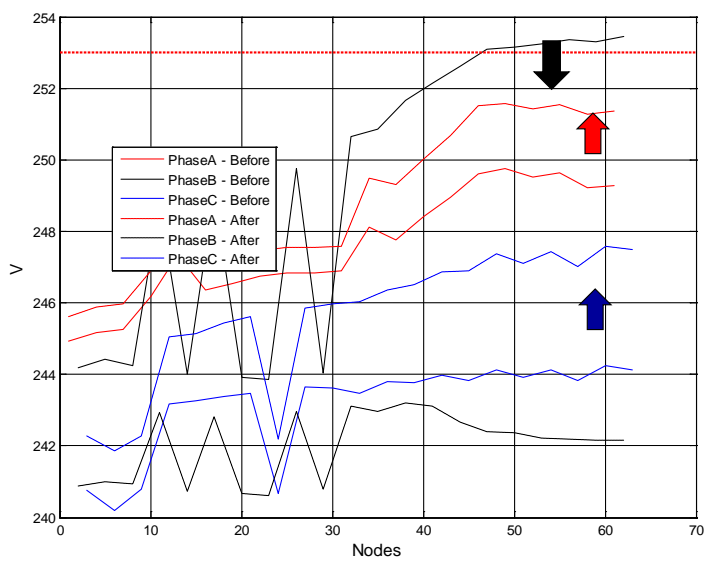

Figure 2. Voltages before and after voltage-driven PV disconnections

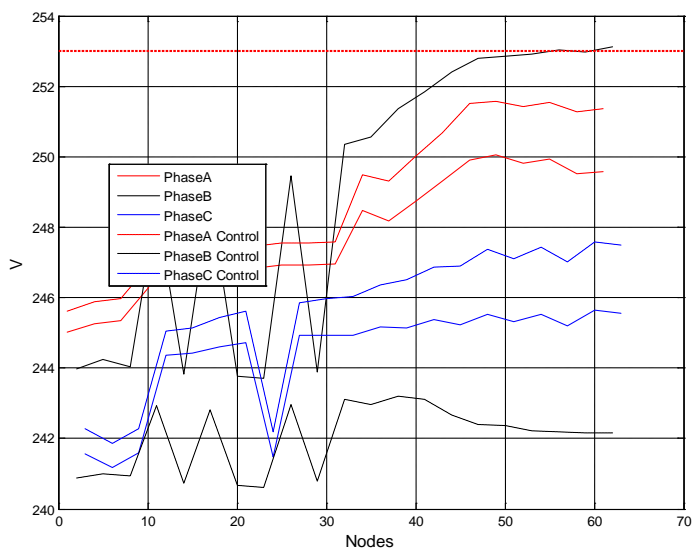

Figure 3. Voltages with and without control after voltage-driven PV disconnections

\section{METRICS AND RESUltS}

\section{A. Metrics}

To understand to which extent, the PV disconnections can impact the operation of LV networks, the following metrics will be analysed:

Voltage increase after PV disconnections: This is the maximum value among the average voltage increase in all of the nodes in one particular phase in one period after voltagedriven PV disconnections. This metric gives an idea about how big is the increase in voltage after a disconnection. A negative number would imply a reduction in the voltage in the three phases.

The voltage rise produced by certain PV disconnections is not necessarily enough to produce the subsequent disconnection of further PV panels as their voltage might not increased significantly. Therefore, to measure the risk of cascading, two additional metrics are developed:

Number of cascading disconnections: This is the number of $\mathrm{PV}$ panels disconnected in the period after voltage-driven PV disconnections only due to the voltage rise specifically produced because of that previous disconnection (as explained in section III). It is important to remark that this number is a subset of the number of PVs disconnected (the disconnection could be because previous PV disconnections and/or because the increase in the power generation/sun irradiance).

Cascading length: This is the number of consecutive periods in which a cascading disconnection is produced. This metric is a good indicator about the actual cascading nature.

\section{B. Results}

Two disconnection limits (phase-to-neutral voltages) are analysed: 1.1 and 1.14 p.u (253 and 262.2V, respectively). These limits are embedded in the local control strategy of each of the modeled PV panels. The three metrics presented above are used to quantify the performance of each limit in the context of PV disconnection cascading. For simplicity, the graphical results are presented only for feeder 1 (Fig. 1).

\section{1) Voltage Disconnection Limit of $1.1 \mathrm{p.u}$}

Fig. 4 shows the histogram of the voltage increase after a voltage-driven disconnection. There, it is possible to observe that in most cases the PV disconnection in one phase produces a voltage rise in at least one of the other phases. Only in a few cases there is a voltage reduction in all the phases (negative voltage increases in Fig. 4).

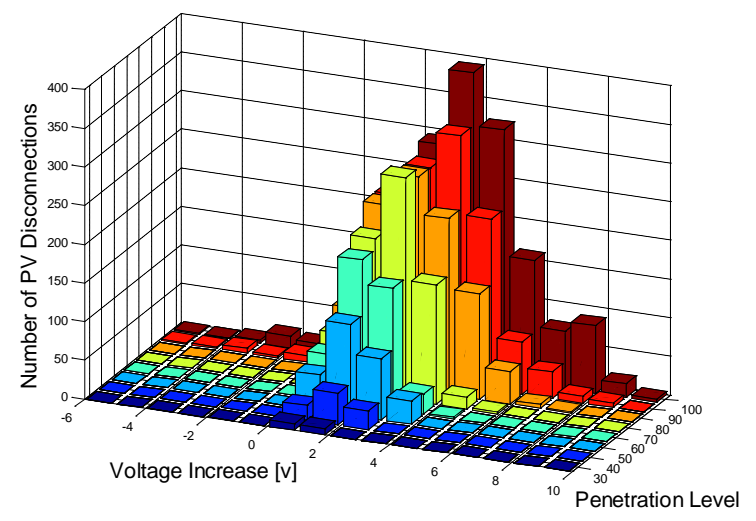

Figure 4. Voltage increase after PV disconnections 


\section{Accepted Paper}

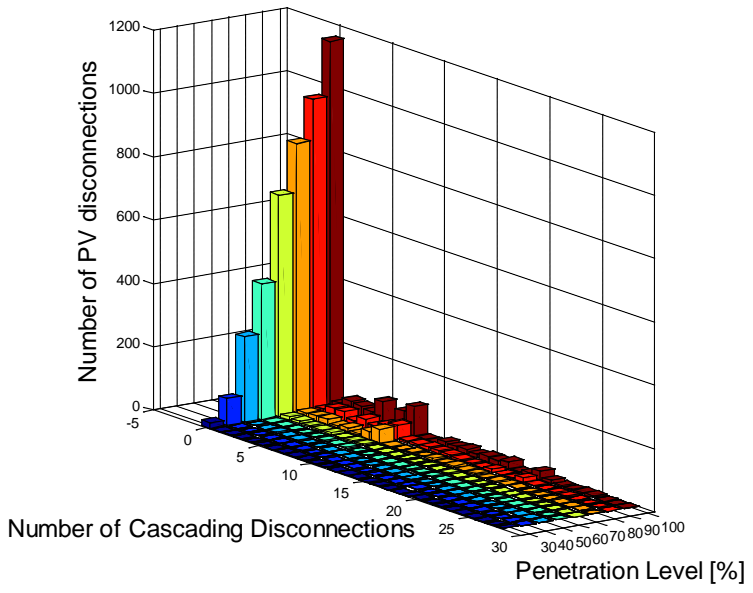

Figure 5. Histogram of the number of cascading disconnections

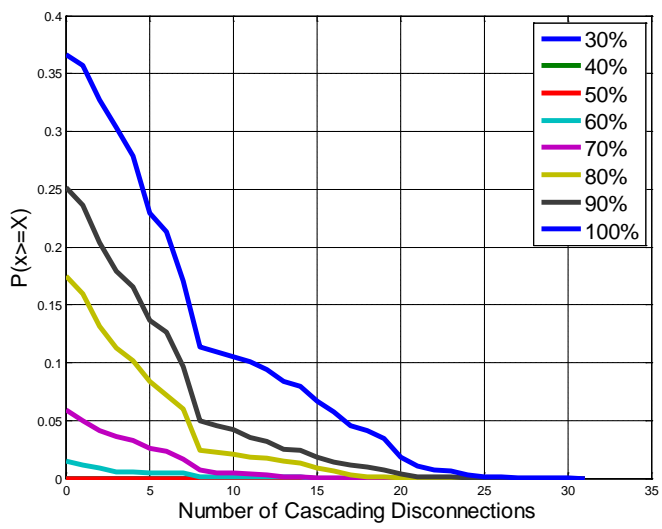

Figure 6. Histogram of the number of cascading disconnections

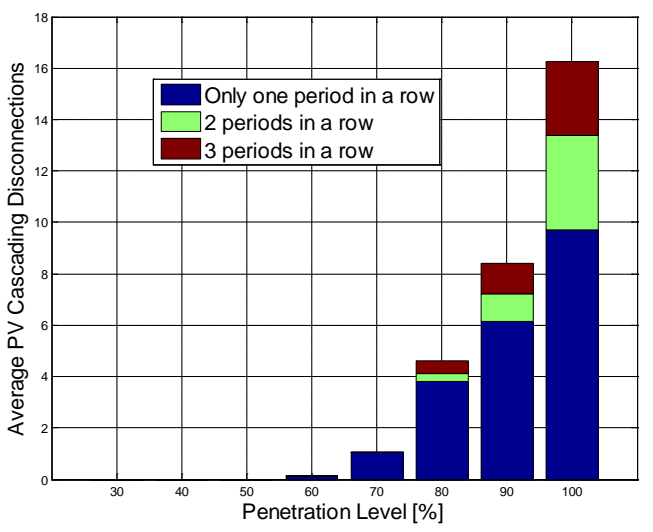

Figure 7. Cascading Length

Fig. 5 presents the histogram of the number of cascading events; this corresponds to the cases when the voltage increase after a voltage-driven PV disconnection is big enough to produce a new disconnection. In most cases, there are no cascading events (leftmost column in Fig. 5). However, there are some cases where the risk of cascading is not zero. Indeed, by using the information provided in Fig. 5, it is possible to create the cumulative probability distribution for the number of cascading disconnections. This is done in Fig. 6 where the probability to have more than $\mathrm{x}$ number of cascading disconnection for each penetration level is presented. For example, the probability to have more than 10 cascading disconnections during the day is 0.05 and 0.1 for $90 \%$ and $100 \%$ of penetration level, respectively.

Finally, cascading disconnections happen mostly in the period after the first automatic disconnection(s) as can be observed in Fig. 7. Consequently, the actual cascading nature is very limited. Furthermore, it is important to mention that only feeders 1 and 4 present PV cascading disconnections as shown in Table 2. Specifically, this table contains a summary of the results for all of the analysed feeders. It presents in the second column the penetration level when the first PV cascading disconnections appear. The third column shows the probability to have more than one PV cascading disconnection at $100 \%$ of penetration level.

TABLE 2

LENGTH AND CUSTOMER NUMBER PER FEEDER

\begin{tabular}{c|c|c}
\hline Feeder & $\begin{array}{c}\text { First cascading } \\
\text { disconnections }\end{array}$ & $\begin{array}{c}P(x \geq 1) \text { at } \\
100 \%\end{array}$ \\
\hline 1 & $60 \%$ & 0.35 \\
\hline 2 & None & 0 \\
\hline 3 & None & 0 \\
\hline 4 & $90 \%$ & 0.25 \\
\hline 5 & None & 0 \\
\hline 6 & None & 0 \\
\hline 7 & None & 0 \\
\hline
\end{tabular}

2) Voltage Disconnection Limit of 1.14 p.u

The same analysis is carried out using $262.2 \mathrm{~V}$ as the voltage disconnection limit in the control strategy.

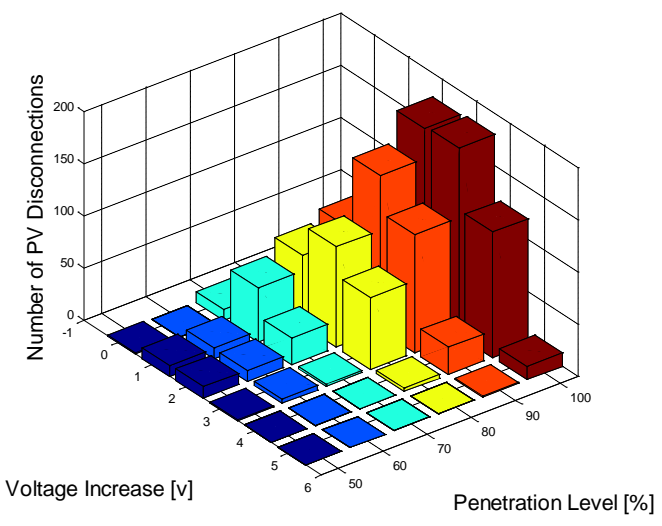

Figure 8. Voltage increase after PV disconnections

From Fig.8 it is possible to observe that the number of PV disconnections is lower than with the previous voltage limit. Moreover, PV disconnections start at higher penetration level but the magnitude of the voltage increase after disconnections is lower in comparison with the 1.1 p.u. case. This happens because more PV panels are likely to be disconnected at the same time when the voltage limits is lower, thus the problems will appear earlier and they will be larger. In this case, for the network under analysis, the voltage rise after a PV disconnection was not enough to produce a cascading disconnection for any of the scenarios and feeders simulated. 


\section{Accepted Paper}

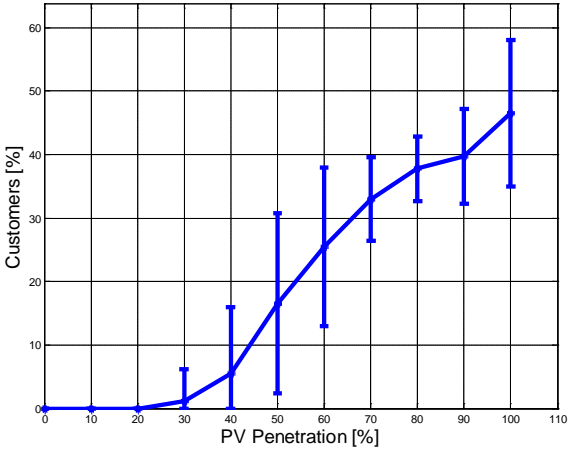

Figure 9. Percentage of customers with voltage problems without control

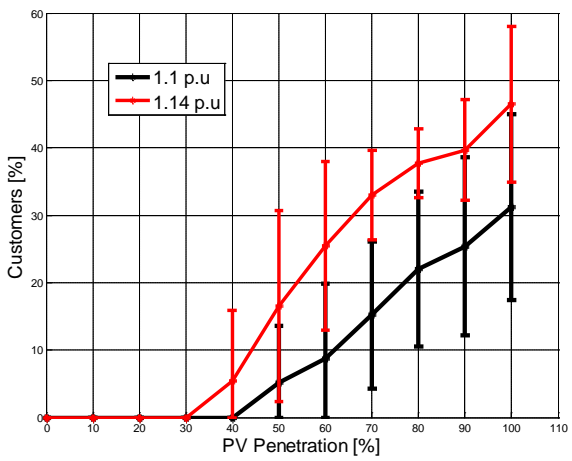

Figure 10. Percentage of customers with voltage problems with control

\section{DISCUSSION}

As mentioned before, the lower limit for the voltage disconnection can produce higher voltage rise and therefore could increase the probability of having PV cascading disconnections. However, it cannot be forgotten that this limit is introduced to reduce the appearance of voltage rise. To analyse this effect, the percentage of customers with voltage problems is determined for the case without control and for the cases with automatic disconnection at $253 \mathrm{~V}$ and $262 . \mathrm{V}$.

The percentage of customers with voltage problems takes the voltage profile calculated for each customer and checks compliance with the European Standard EN 50160 [12]. If the standard is not satisfied, then the costumer has a problem. All the customers with problems are added up, and this number is divided by the total number of customers in the feeders [3]. For instance, Fig. 9 shows this metric for the case without any control strategy for feeder 1 . Since one hundred scenarios were run per penetration level, this graph depicts the average value +/- one standard deviation. In this case, it suggests that voltage problems appear at $30 \%$ of penetration level.

The percentage of customers with voltage problems for the cases with local control strategy are presented in Fig. 10. In this figure, it is possible to observe that the case with voltage disconnection at 1.1 p.u delays the appearance of voltage problems from $30 \%$ (Fig. 9) to 50\% (Fig. 10). The magnitude of the problems (\% of customers affected) is also lower in the case with the lower disconnection limit. In contrast, in the case with a higher voltage disconnection, the problems start one penetration level after the base case, and the magnitude of the problems is almost the same.

\section{CONCLUSIONS}

The potential risk of PV cascading disconnection in LV feeders was analysed in this work. The automatic voltagedriven PV disconnection was considered in a real UK LV network. The corresponding cascading risk were quantified by using a Monte Carlo approach in order to cater for the uncertainties related to demand as well as location and size of PV.

The main results indicate that the risk of cascading is not zero in LV distribution networks. However, the number of cascading disconnections is likely to be small (although increases with the penetration of PV). Moreover, cascading disconnections happen mostly in the period after the first automatic disconnections. Consequently, the actual cascading nature is very limited. In addition, it was also shown that a smaller voltage limit for the disconnection of PV was more beneficial in terms of PV penetration and customers affected.

\section{ACKNOWLEDGMENT}

The authors would like to thank the funding and technical support provided by Electricity North West Limited (ENWL) during this work.

\section{REFERENCES}

[1] R. A. Walling, R. Saint, R. C. Dugan, J. Burke, and L. A. Kojovic, "Summary of Distributed Resources Impact on Power Delivery Systems,” IEEE Trans. Power Deliv., vol. 23, no. 3, pp. 1636-1644, 2008.

[2] M. Begovic, I. Kim, D. Novosel, J. R. Aguero, and A. Rohatgi, "Integration of Photovoltaic Distributed Generation in the Power Distribution Grid," in 45th Hawaii International Conference on System Sciences, 2012, pp. 1977-1986.

[3] A. Navarro-Espinosa, L. F. Ochoa, and D. Randles, "Monte CarloBased Assessment of PV Impacts on Real UK Low Voltage Networks,” in 2013 IEEE Power \& Energy Society General Meeting, p. in press.

[4] Energy Network Association, "Engineering Recommendation G83 Issue 2,” 2012.

[5] R. Tonkoski, D. Turcotte, and T. H. M. El-Fouly, "Impact of High PV Penetration on Voltage Profiles in Residential Neighborhoods,” IEEE Trans. Sustain. Energy, vol. 3, no. 3, pp. 518-527, Jul. 2012.

[6] Brisitsh Standards Institution, "BS EN 50438:2007 Requirements for the connection of micro generators in parallel with public low voltage distribution networks," 2007.

[7] P. D. F. Ferreira, P. M. S. Carvalho, L. A. F. M. Ferreira, and M. D. Ilic, "Distributed energy Resources Integration Challenges in LowVoltage Networks: Voltage Control Limitations and Risk of Cascading,” IEEE Trans. Sustain. Energy, vol. 4, no. 1, pp. 82-88, 2013.

[8] K. Fekete, Z. Klaic, and L. Majdandzic, "Expansion of the residential photovoltaic systems and its harmonic impact on the distribution grid,” Renew. Energy, vol. 43, pp. 140-148, Jul. 2012.

[9] I. Richardson and M. Thomson, "Intagrated simulation of Photovoltaic Micro-Generation and Domestic Electricity Demand: A one minute resolution open source model," in CREST - Department of Electronic and Electrical Engineering, Loughborough University, UK., 2010.

[10] Office for National Statistics, "Families and households, 2001 to 2011,” Stat. Bull., no. January, pp. 1-14, 2012.

[11] Department of Energy and Climate Change, "Weekly Solar PV Installation and Capacity based on Registration Date,” 2012.

[12] Brisitsh Standards Institution, "BS EN 50160: Voltage characteristics of electricity supplied by public distribution systems,” 2000.

[13] Electric Power Research Institute - EPRI, "Open Distribution System Simulator,” $2012 . \quad$ [Online]. Available: http://sourceforge.net/apps/mediawiki/electricdss. 